\title{
Ubiquitous Computing and Its Applications in the Disease Management in a Ubiquitous City
}

\author{
Javier Cabo Salvador1,2,3,4,5,6,7, Jose Miguel Ramirez Uceda², Verónica Cabo Muiños,4,4, \\ Javier Ramos Lopez ${ }^{4,5,6}$, Carlos de Castro ${ }^{2,3,4,5}$ \\ ${ }^{1}$ Cátedra de Telemedicina, Universidad Internacional de Andalucía, Seville, Spain \\ ${ }^{2}$ CITEC, Centro de Investigaciones Tecnológicas Universidad de Córdoba, Córdoba, Spain \\ ${ }^{3}$ Cátedra de Gestión Sanitaria y Ciencias de la Salud, UDIMA, Madrid, Spain \\ ${ }^{4}$ IHM-Medical Technology, Madrid, Spain \\ ${ }^{5}$ Fundación de Ingeniería Biomédica, Madrid, Spain \\ ${ }^{6}$ Escuela Técnica Superior de Ingenieros de Telecomunicación, Universidad Rey Juan Carlos, Madrid, Spain \\ ${ }^{7}$ Departamento Cardiovascular Hospital Vithas NISA Pardo de Aravaca, Madrid, Spain \\ Email: jcabo@telefonica.net
}

How to cite this paper: Cabo Salvador, J., Uceda, J.M.R., Muiños, V.C., Lopez, J.R. and de Castro, C. (2018) Ubiquitous Computing and Its Applications in the Disease Management in a Ubiquitous City. Journal of Computer and Communications, 6 , 19-42.

https://doi.org/10.4236/jcc.2018.63002

Received: November 9, 2017

Accepted: March 17, 2018

Published: March 20, 2018

Copyright $\odot 2018$ by authors and Scientific Research Publishing Inc. This work is licensed under the Creative Commons Attribution International License (CC BY 4.0).

http://creativecommons.org/licenses/by/4.0/

\begin{abstract}
The actual challenge in health is to manage patients with chronic diseases from a holistic approach where technology around the patient and at the city enhances their wellness. This paper deepens in the relations between health, devices, and models of technological cities and how these can be modeled to provide a more cost efficient solution while less invasive and more natural to the end users. In light of this, usable and accessible software and a wide range of devices, ranging from PC, smartphone, tablet and SmartTV have been tested. This manuscript will give good comprehension on how technology and disease management care models interact with the patient.
\end{abstract}

\section{Keywords}

U-Health, Ubiquitous Computing, Internet of Things, Spimes

\section{Introduction}

Patients with chronic diseases, their management (process management) and their integral treatment (socio-health care) represent one of the main current challenges for health systems in any country [1]-[15]. The advance in the management of chronic diseases and in the management of patients with multiple pathologies (patients with two or more chronic pathologies), requires a paradigm shift of our usual concepts of management of acute patients within the $\mathrm{Na}$ tional Health Systems (NHS), and that the current conceptual frameworks are 
transformed, so that holistically, the citizens, their environment and their socio-health needs are the real center of the health system [16]-[24].

We are fully involved in the third great revolution of humanity, the Technological Revolution, initiated with the change of analogical, mechanical and electronic technology, to digital technology aimed at singularity, with radical changes caused by computing and ICT and where the raw material is information transformed into data, whether structured or unstructured. In medicine we are moving towards the singularity and the future of medicine lies in the multidisciplinary integration with genetics and molecular biology, biomedical engineering (biotechnology), artificial intelligence, robotics, and nanotechnology, in search of a Hospital without Barriers.

Thanks to the great development of biosensors and ubiquitous computing and environmental intelligence the data to be managed, (biological data such as ECG, Sat 02, Blood Pressure, Heart Rate, Temperature...), can be digitally transferred. This allows making remote diagnoses using uHealth platforms that allow us to offer a set of applications for patients, and professionals in the socio-health sector. Through an intuitive interface, it is possible to access the different uHealth services that range from medical care with video consultations, e-check and hospitalization at home, tele-education services for health and clinical sessions between professionals. This can be done using videoconferences, or to be broadcasted in 3D using videostreaming, which allows drawing a real scenario of hospital without barriers, being key tools in the new models of integrated sanitary management and in the processes of socio-sanitary attention and care of people with dependence.

In this scenario, the patient will be surrounded by autonomous sensors (scales, tensiometers, ECG recorders, and other devices that can be implanted in the skin or tissues, through environmental sensors of temperature, humidity, position, etc. that form networks ad hoc, be they BAN (Body Area Network), PAN (Personal Area Network) and/or HAN (Home Area Network), acquire and transmit all the information of interest.

At the end of the 1980s, researchers at Xerox's Palo Alto Research Center (PARC) distanced themselves from personal computing-what they identified as being dominated by computers-into what they called ubiquitous computing, which "merges with the natural human environment and allows computers to vanish in the background" [25]. In other words, they were interested in "invisible" computers that allowed us to focus on living beyond computational devices. According to Weiser, ubiquitous computing would not only free us from the limitations of desktop computing, it would also free us from insulating environments such as immersive or virtual reality environments. According to Weiser, from the perspective of design, ubiquitous computing concentrated more on cultural and social aspects than on technological ones [26]. Unfortunately, Weiser died and although the concept of ubiquitous computing continued to expand, the social or cultural (non-technical) aspects are still insufficiently explored and represented in the design process (Figure 1). 


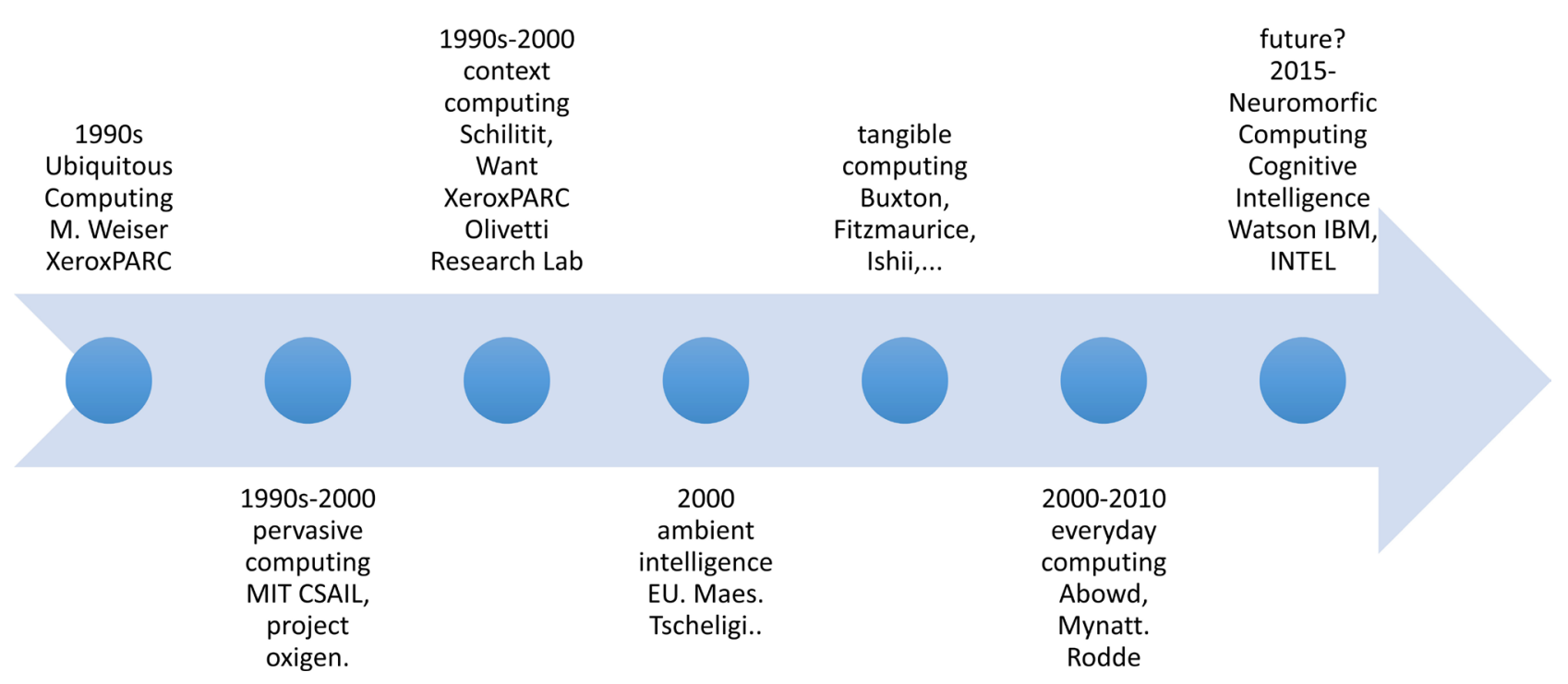

Figure 1. Evolution of ubiquitous computing. MIT (own adaptation).

In 1996, Weiser and Seely Brown predicted the "advent of calm technology" [27], being the main derivative from the perspective of the software of calm technology in the Internet of things (IoT). The concept of the Internet of Things is still in a discussion phase, where different authors propose different views of how the devices and information networks should be integrated. The initial vision of the Auto-ID Center was to "tag" all existing objects and people and manage them through ubiquitous computing. This system would be able to instantly identify any entity every "tagged element". The Internet of things must code from 50 to 100,000 million objects and follow the movement of these. Every human being is surrounded by 1000 to 5000 objects [28].

The concept crystallizes under the definition of Spime [29]. Spimes are "things" located in the real world that have a unique digitally readable identity; they are traceable ; they can be searched from search engines; recyclable; designed and stored virtually and in many cases, they can be manufactured by the user and allow intelligence and interaction processes.

Another alternative view, from the world of the semantic Web, focuses instead on making all things (not just tagged ones) have an address based on any of the existing protocols, such as URI. The objects, the things, do not converse, but in this way they could be referenced by other agents, such as powerful centralized servers that act for their human owners is what we call Ambient Intelligence. This vision is the one that is reigning today with the use of supercomputers based on neuromorphic computing and Cognitive Computing platforms such as IBM's Watson.

In recent years researchers on issues related to information technology and communications have defined a term called "Ambient Intelligence" or Environmental Intelligence (EnI). The concept of Environmental Intelligence poses a new way of understanding the way people interact with technology. It describes an environment that perceives, adapts and responds to the presence of people. 
The EnI vision places the person at the center of future developments. Moreover, technology must be developed to People, instead of people adapting to technology, EnI offers the possibility that in any everyday environment (home, moving on the street, in transport, in public places, in hospitals...) users may have integrated intelligence that facilitates daily life [29].

In the broadest sense, ubiquitous computing comprises any number of mobile, portable, distributed and context-sensitive computer applications. In this sense, ubiquitous computing could be the investigation of "how information technologies can be imbued in everyday objects and how they can lead to improvement and help for people's lives".

Interesting types of ubiquitous computing are those that openly seek to create unique forms of habitable space and ways of living. These types, when used in daily life, bring out not only spatial aspects, but also temporalization and sociocultural aspects. The Internet of things represents a great advance in the challenge of data acquisition, while cognitive computing provides the intelligence necessary to the prediction of knowledge.

\section{Neuromorphic Computing \& Cognitive Intelligence in Ubiquitous Cities}

The objective of cognitive computing is to simulate human thought processes in a computerized model. Using self-learning algorithms that use data mining, pattern recognition, and natural language processing, the computer can mimic the way the human brain works. When we speak of "cognitive", we refer to the ability to process information, learn, reason, memorize, solve problems and make decisions. We can say that we are using "cognitive computing" when machines imitate those cognitive functions to make them intelligent.

Machine Learning is a subset of artificial intelligence that allows researchers, data scientists, engineers, and analysts to build algorithms that can learn and make predictions based on data. Instead of following a specific set of rules or instructions, an algorithm is trained to detect patterns in large amounts of data. In its most basic form, it is about making the machines learn, and in order for them to learn it is necessary to give them information, to provide them with data called "training data".

Deep Learning is a type of machine learning that today represents the most advanced form of neural networks, artificial intelligence models based on the behavior of the nervous system. The algorithms of Deep Learning are very promising, but until today they have not been able to replicate the ordinary creative human capacity. It is then a bit premature to expect these algorithms to be creative.

On the other hand, Machine Learning helps cognitive systems to learn, reason and participate with us in a more natural and personalized way. The more information and feedback you have from the users, the more intelligent the system will become. 
Neuromorphic computing is the future, where it is expected to mimic the way the human brain works by replacing current circuits based on transistors with an architecture inspired by nerve cells or neurons.

The benefits of this approach offer more than speed. Charles Augustine, a scientist at Intel Circuit Research Labs, suggests that "neuromorphic designs may need a calculation energy between 15 and 300 times lower" compared to the latest generation CMOS designs. It is the ideal technology for tasks based on analysis, such as data detection, adaptive $\mathrm{AI}$, associative memory and cognitive computing. The low power neuromorphic hardware can be perfect for future supercomputing systems, especially as we move from the petascale era (machines measured in petaflops, i.e., a quadrillion calculations per second) to an exascale (machines calculated in exaflops, quintillion calculations per second).

The implementation of computerized cities that adapt to the functional diversity of users, their interests and needs and that incorporate imbued intelligence are the best hope we have of achieving sustainable development for all without the need of compromising human intervention [30].

Figure 2 shows the different stages that have been traversed until the definition of this concept according to the infrastructure, services and the interaction that the latter offer with people.

The Ubiquitous City aims to materialize a new way of understanding the way in which people interact with technology according to the concept of "calm technology" [27]. It places the person as the center of the new city and the new services. It allows the best practices for active aging by using Environmental Intelligence and Cognitive Intelligence: The person is located at the center of development on the daily environment, facilitating daily life and improving their quality of present and future life.

With Ubiquitous Computing and the Ubiquitous City, one more step is taken in the evolution of human-machine interaction seeming human-human interaction.

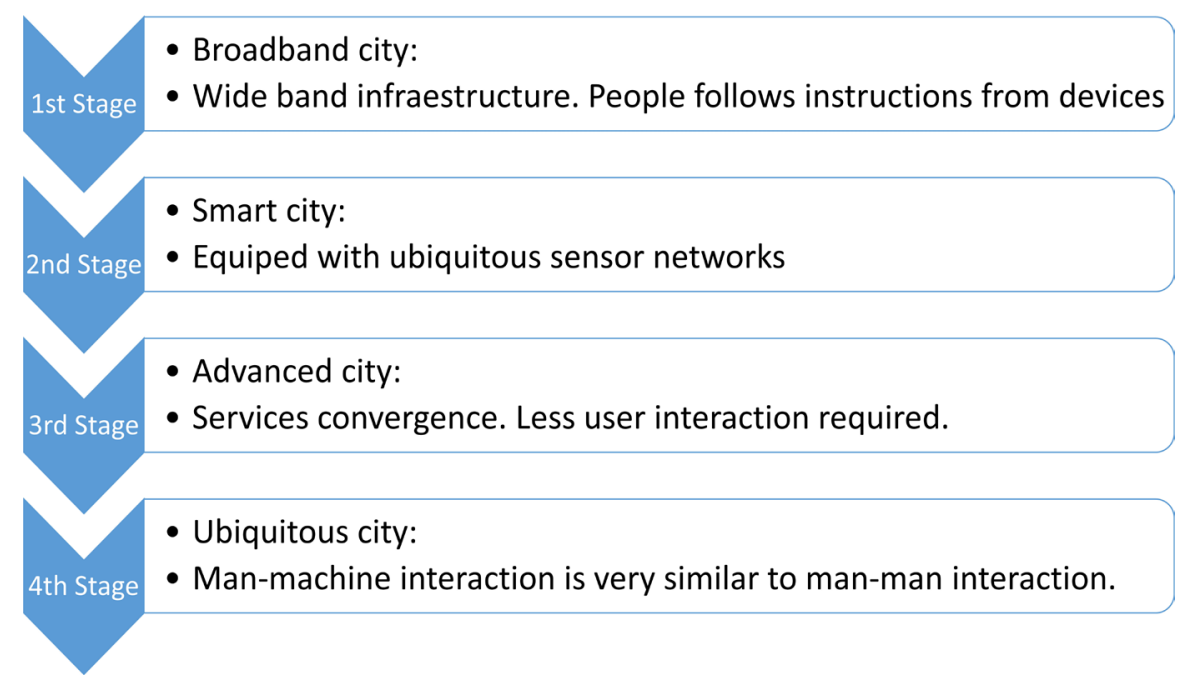

Figure 2. Evolution of the U-City. 
Regarding the infrastructure, the Ubiquitous City proposes a vision of the "Internet of Things" where the new objects in the technoculture universe have to be "Spimes" [29]. That is, things that are located both in the urban space and in the domestic space, that have a unique digitally readable identity, are traceable, can be searched from search engines, recyclable designed and stored virtually and, in many cases, can be manufactured by the user.

The Ubiquitous City is a futuristic city of the $21^{\text {st }}$ century that enables ubiquitous computing services with cognitive intelligence, resource management and access to information. This type of city maximizes the standard of living and the value of a region through the innovation of each function of the city. It merges high-tech infrastructure and ubiquitous services in the urban area. The Ubiquitous City is the highest level of information city that can innovate every function of the city in aspects such as the quality of urban life, safety, citizen welfare and the creation of new health management services. The Ubiquitous City is the convergence between construction, information technologies, content and cognitive intelligence.

After the appearance of the Report on Our Common Future coordinated by Gro Harlem Brundtland within the framework of the United Nations [31], the objective of "sustainable development" was promoted, meaning that it allows "to satisfy our current needs without compromising the ability of future generations to meet theirs". The concept of Ubiquitous City adapts quite well to the sustainable management of our lives without generating the perception of a negative impact on the part of the final user (Ubiquitous Cities and Sustainable Cities).

Currently all sustainable cities in planning are ubiquitous cities and there are currently no ubiquitous cities in planning that are not sustainable. Examples of this can be found among the eight most powerful projects of Sustainable Cities [32]: New Songdo, Dongtan, Masdsar City, Sino-Singapore Tianjin Eco-City, Sino-Singapore Nanjing Eco High-Tech Island, IT Valley Plan, Meixi Lake District, Sitra Low2No; of which New Songdo, Sino-Singapore Nanjing Eco High-Tech Island and IT Valley Plan, are born with the approach of being both ubiquitous.

In this ubiquitous city environment, with the help of ubiquitous computing and current data management platforms, it becomes possible to manage chronic patients and Disease Management in an easy, effective and efficient way.

\section{Disease Management and Ubiquitous Computing}

The existing models of management of patients with chronic diseases that require processes and hybrid care, not only health but also social (socio-health processes) are few and very young in their approach, all deriving from the initial Chronic Care Model (CCM), developed by Ed Wagner and collaborators at the MacColl Institute for Healthcare Innovation in Seattle (USA), to improve the management of chronic diseases within the systems of integrated providers, such as the North American Group Health Cooperative and Lovelace Health System 
[33]. This Model of Chronic Care (CCM), recognizes that the management of chronic diseases is the result of the interactions of three overlapping areas:

1) The community or country as a group, with its health policies, its health model and its multiple public and private resources;

2) The health system, with its funding and provider organizations and public and private insurance systems;

3) Clinical practice or health care, primary and specialized, identifying those essential interdependent elements that must interact not only effectively and effectively, but also efficiently, to achieve optimal care for patients with chronic diseases.

The ultimate purpose of this model is to place patients actively and well informed as a central element of a system that has a dynamic team of professionals with the necessary knowledge and experience (Figure 3).

This model was the first widely disseminated system and the one that served as the basis for all subsequent models such as the later Extended Chronic Care Model (ECCM), used and proposed by the Government of British Columbia of Canada, which emphasizes the importance and relevance of the community context, as well as the importance of prevention and health promotion (Figure 4), to the creation of the Framework for Innovative Care for Chronic Diseases (ICCC), of the World Health Organization (WHO), which are basically variants of the original model of Wagner, and which emphasize on one hand the great importance and urgent need for commitment in the project, not only health, but also the social part, in an integrated way (key to this project), and on the other hand the need to promote at a political and cultural level the promotion of

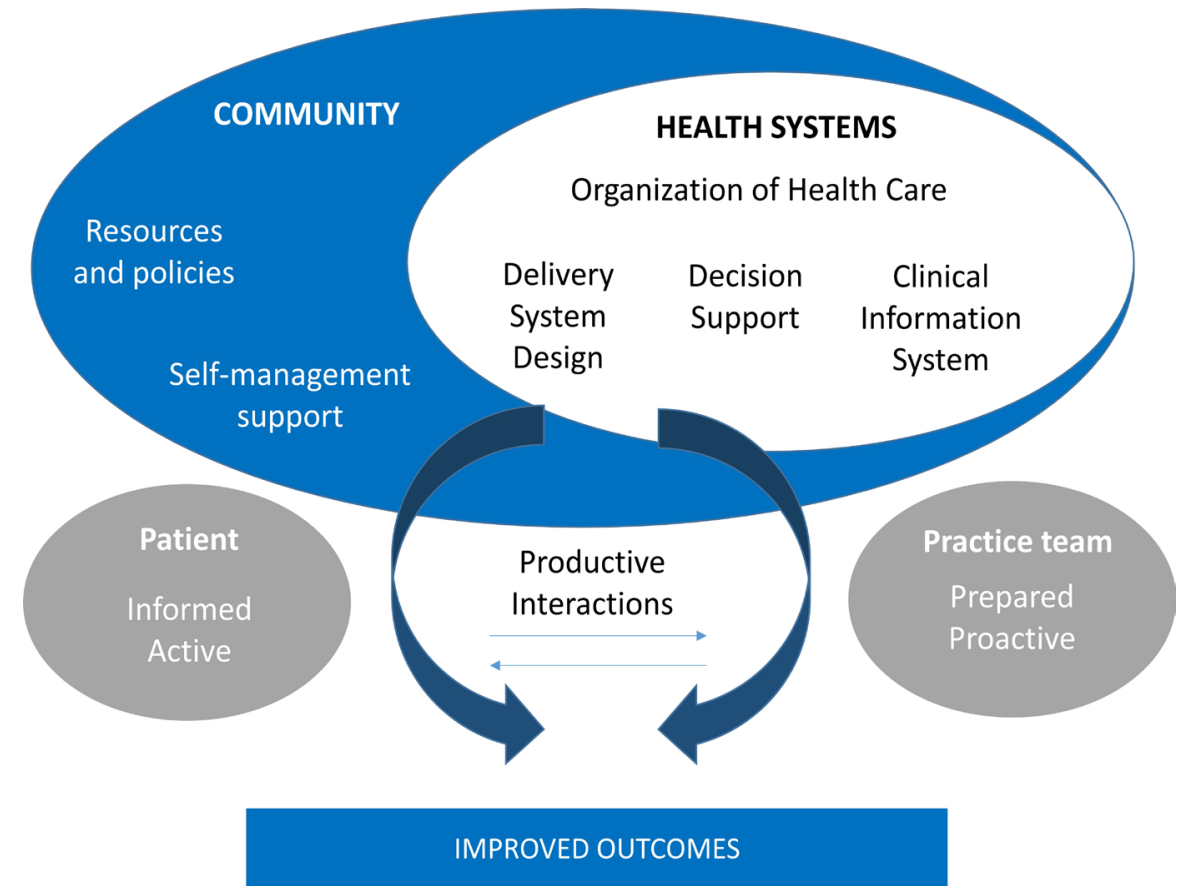

Figure 3. Chronic care model. Source: MacColl Institute for Healthcare Innovation, (own adaptation). 


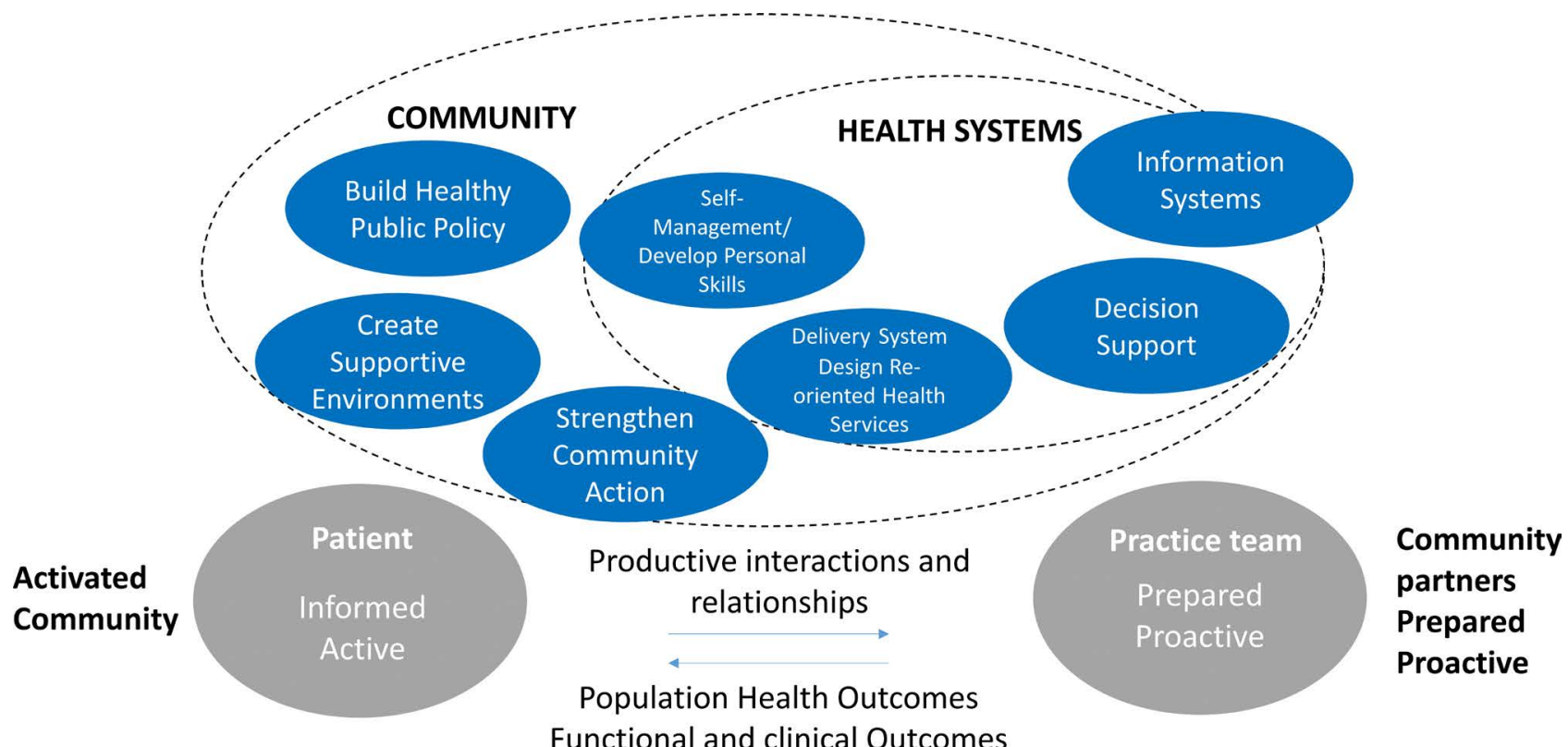

Figure 4. Extended chronic care model (ECCM). Source: Ministry of Health, Government of British Columbia (own adaptation).

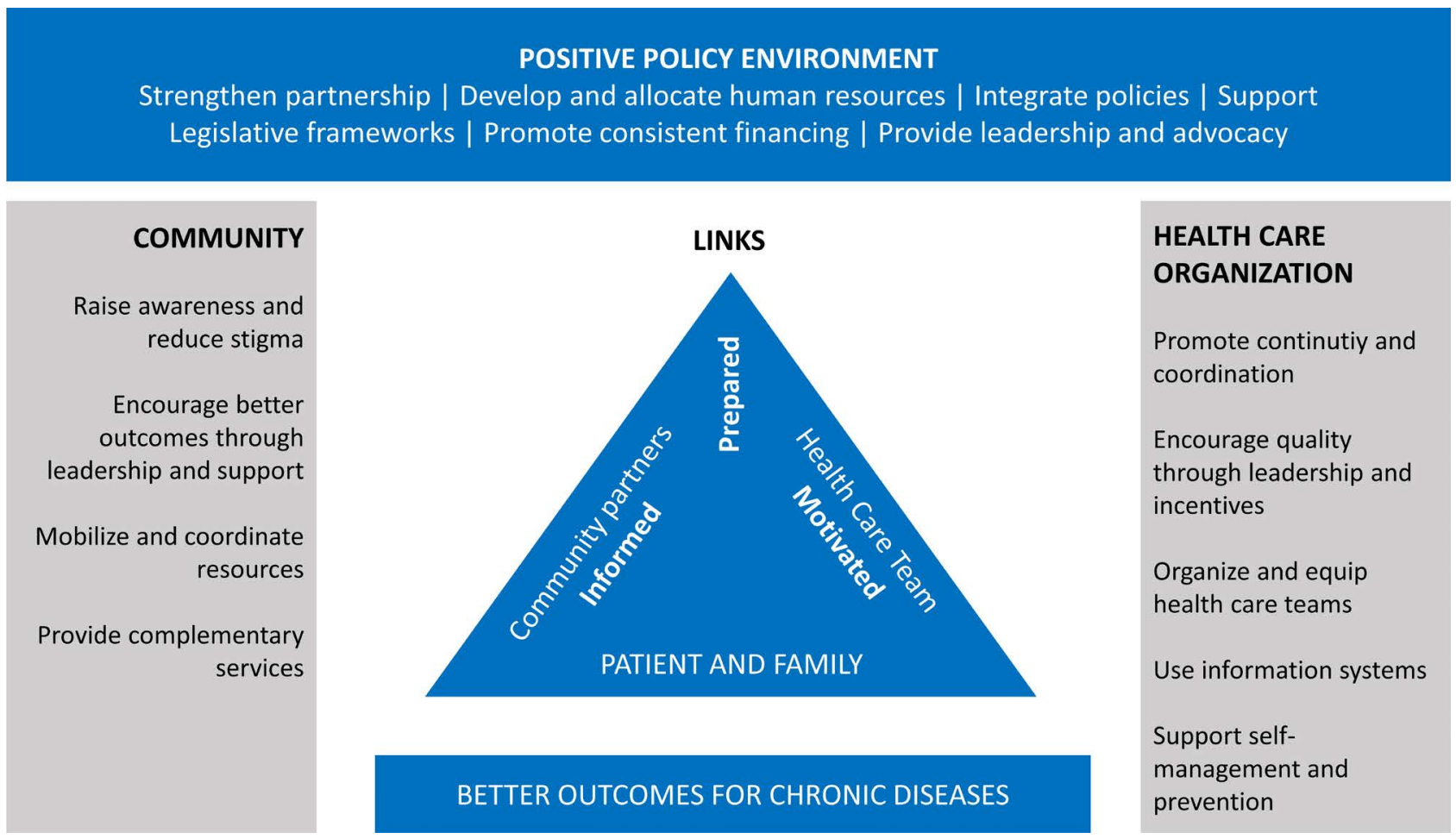

Figure 5. WHO, innovative care framework for Chronic Conditions, 2002. Source: WHO, Innovative Care for Chronic Conditions (own adaptation).

health and the prevention of diseases, together with the need to optimize the use of existing resources, making comprehensive management effective, effective and efficient, through the formulation of integrated socio-health policies [34] [35] [36] [37] [38] (Figure 5).

This Innovative Care for Chronic Condition of the WHO (ICCC) makes sev- 
eral key complementary contributions to the Chronic Care Model (CCM):

1) At the level of macro-management, the need for the existence of a unitary and strong socio-health policy that can redirect socio-health services and guide them towards the real needs of patients with chronic pathologies is highlighted, this being a key primary element of the model with a strong direction, and with both inter-territorial and intersectoral collaboration, which contributes to the model a real integration of policies, financial sustainability and the contribution of prepared and qualified human resources.

2) At the level of mesogestion, the attention in this model continues to be centered as that of Wagner, in the active role of community agents, but emphasizing the great importance of integration and coordination of social health services.

3) At the level of micromanagement, the established and existing interaction within the Chronic Care Model (CCM) between health professionals and patients (binary interaction) is broadened by involving the community and replacing the term "activated" with reference to the patients for the new patient term "motivated and prepared" (Table 1).

Patients with multiple chronic diseases, multi-pathological patients, or those with long-term needs not only health but also social, with a functional deficit that prevents normal and adequate daily activities, becoming fully dependent, are patients that consume the largest volume of health resources in a country, so the creation of new management models valid for the management of this type of citizens remains a national challenge [39] [40] [41] [42].

In the historical moment we are living, the organization of health and socio-health care, aimed at the management, management and treatment of these multi-pathological patients is totally inappropriate, and it is necessary to promote and encourage the work of multidisciplinary teams (health professionals and health professionals). social services acting simultaneously and in a synergistic and coordinated way) so that it can be guaranteed a social and health care in a comprehensive manner and with equity, which provides a continuity of long-term care together with an improvement in the quality of care, a more rational use of human resources as well as structural and financial resources (efficiency) that contribute to an improvement in the quality of life of both patients and their family environment, all according to criteria previously defined in the respective Table 1. Key elements of the ICC model.

\begin{tabular}{c}
\hline KEY ELEMENTS OF THE ICCC MODEL \\
\hline EVIDENCE-BASED DECISION-MAKING \\
POPULATION HEALTH FOCUS \\
FOCUS ON PREVENTION \\
EMPHASIS ON QUALITY OF CARE AND SYSTEMIC QUALITY \\
FLEXIBILITY/ADAPTABILITY \\
INTEGRATION AS THE HARD AND FRACTAL CORE OF THE MODEL
\end{tabular}



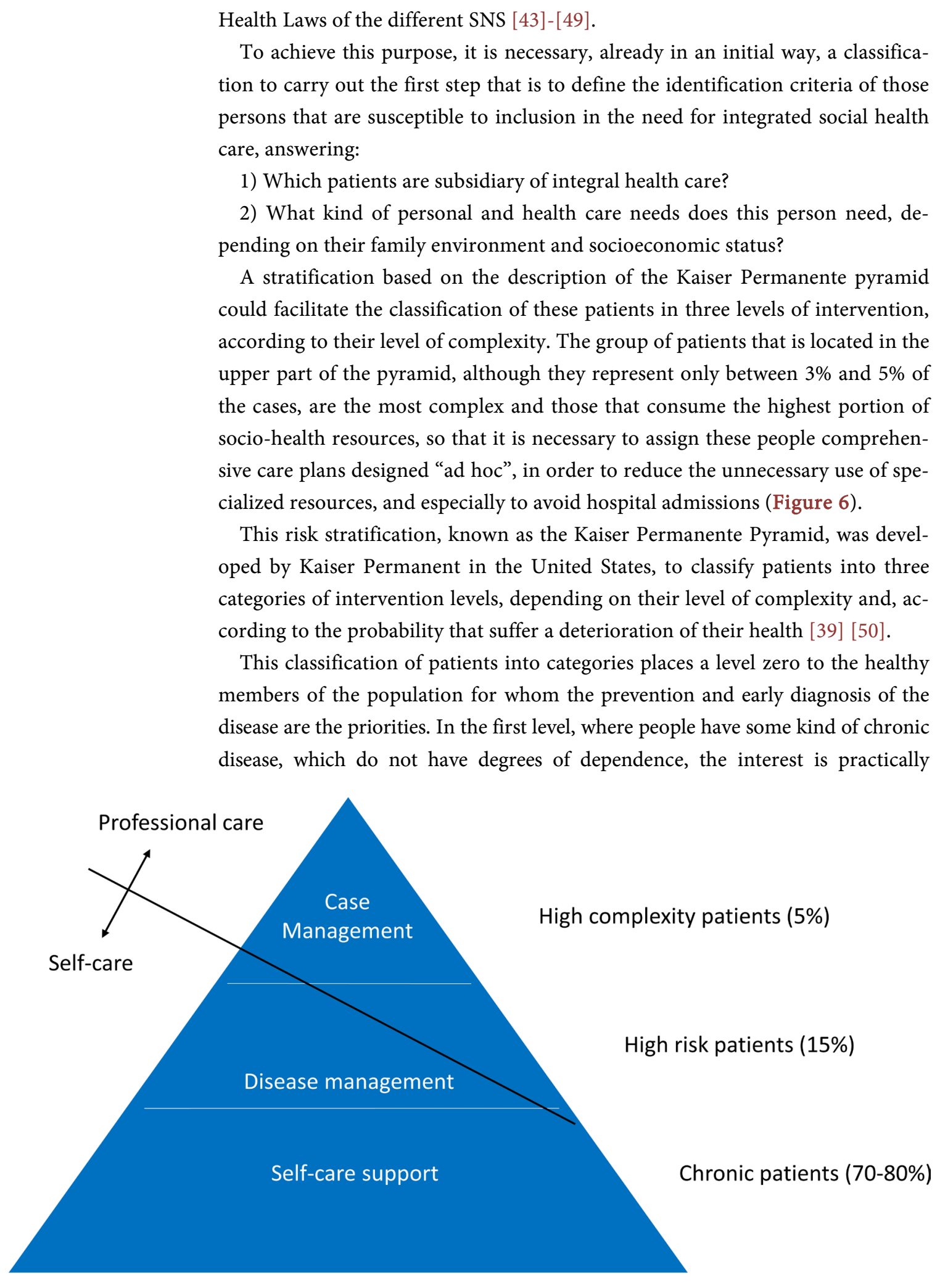

Chronic patients (70-80\%)

Figure 6. Kaiser Permanente risk stratification pyramid (own adaptation). 
oriented to self-care, the appropriate administration of medicines and education in health aspects, with few needs for social and health support, representing this level approximately between $70 \%-80 \%$ of chronic patients. In a second level, high-risk chronic patients are included, who already require a more direct management of the disease and more socio-health support, representing $15 \%$ of patients. At the third level, patients identified as complex are located (from 3\% to $5 \%$ of the total) and to whom care plans are assigned guided by what they call case management projects designed to reduce the inappropriate use of specialist services and avoid hospital admissions [22] [51].

This Kaiser Permanente model has inspired additional approaches, such as the Guided Care Model, where the primary care nursing staff previously trained and qualified and in coordination with a medical team deals with assessment, evaluation, planning, care, follow-up and supervision of those chronic complex patients identified by means of prediction models previously performed.

Some European public health systems, including the National Health Service of the United Kingdom, the National Health Services (NHS), have tried to apply the Kaiser model in their contexts. Others follow the prediction model, using a wide number of methods such as the Adjusted Clinical Group Prediction Model, the Cost of Diagnosis Group (DCGs), Patients with Risk of Hospital Reentry (PARR 1 and PARR 2) and the Combined Prediction Model (CPM) and (ACGs-PM).

Regardless of the model chosen, what is clear is that models specifically designed to improve the management of chronic diseases and patients with multiple pathologies are needed, since there are no practical clinical guidelines that address multiple conditions, or that are designed to allow both primary and specialized care professionals to consider the individual circumstances and preferences of patients with multiple chronic diseases, through a multidisciplinary integration with professionals in the healthcare environment, and professionals in the social care environment [5] [7].

Apart from the management models, it is also necessary to create quality standards for these socio-health services for these patients with multiple chronic diseases, particularly in relation to the coordination of care, the education of patients and caregivers, training in the support of self-care taking in consideration of individual preferences and circumstances, it is necessary to incorporate tools to improve socio-health processes with the help of new technological tools, such as e-health, m-health, u-health, which require powerful platforms that support analysis and management of large amounts of data (Big Data and environmental intelligence (AmI), as well as through the development of services beyond the limits of the current health system [52] [53] [54].

For this purpose, Information Systems are needed, which provide us with data on both the patient and the health aspects, which we can obtain directly from the exploitation of the Minimum Basic Data Set (MBDS), as additional information on the most relevant social and socioeconomic aspects and that it makes it easier 
for managers to make decisions.

This Sociosanitary Information System (SISS) will allow us, on the one hand, to assess the inclusion criteria for the different offers of the socio-health services portfolio that exists at the moment, and on the other hand, to create and share a socio-health history integrated (HSSI), to obtain a specific social and health CMBD (CMBDSS), and to obtain risk adjustment systems that allow us to know the cost of socio-health processes in order to benchmark efficiency and quality and to allocate resources in function of the costs obtained in the different processes of the portfolio of socio-health services established.

These Information Systems (SISS) will allow us as managers:

1) Register patients and assign them an identification code;

2) To facilitate the monitoring of the sociosanitary process with an ABQ (activity based quality) methodology focused on the quality of care, knowing, on the one hand, how the socio-health care processes are carried out (activity based Management, $\mathrm{ABM}$ ) and on the other hand, the cost of each process (activity based costing, $\mathrm{ABC}$ ) and all this taking as axis of the process the patient with sociosanitary needs that has been defined as susceptible person of inclusion;

3) Being able to follow up with a scorecard of the whole process;

4) Finally, carry out an evaluation and benchmarking with integrated socio-health information (health and social) that is available in an integrated socio-health history (HSSI), which is interoperable and accessible both from the social and from the health parcel.

At the level of Health Systems, the Ministry of Health has information systems, and usually has a reference catalog of Social Services along with a database of beneficiaries and users of services, but to get an effective method for planning, efficiency and analysis is necessary to complement them with:

5) A Unique Social History (HSU).

6) A classification of patients according to their etiology and needs: GRASS.

7) A specific social CMBD (CMBDS).

8) A risk adjustment system through an Aggregate Set of Social Attention (CAAS) that allows us to know the cost of social processes in order to make comparisons (benchmarking) of efficiency and quality and allocate resources based on the costs obtained in the different processes of the social services cata$\log$.

9) Integrated Social Assistance Guidelines (GIAS) for the standardization of processes.

10) Cost Assignment Model for Social Care Processes (MACPAS).

11) Tool for the Evaluation of Results in Social Care (HERAS).

All this frame of reference of models, tools and methodologies is what we call MIGRAS: Integral Model of Management and Results in Social Attention. The MIGRAS model follows the pattern initiated in health, which has led to products such as DRGs (Related Groups for Diagnosis), GCAs (Adjusted Clinical Groups) and similar ones; it looks for common aspects in the users of the social services 
that allow the establishment of classifications that allow grouping the attention processes, providing them with indicators and being able to compare their performance and the effectiveness of their results. In addition, one of the expected benefits is to have information and tools to forecast future needs.

This set of systems and tools will allow us to:

12) Register users of social services univocally and have a comprehensive view of the services they use and their family environment or coexistence.

13) Facilitate the monitoring of the social process with an ABQ methodology (Activity Based Quality) focused on the quality of care, knowing on the one hand how the processes of social care (Activity Based Management, ABM) are carried out and on the other hand, the cost of each process (Activity Based Costing, $\mathrm{ABC}$ ).

14) Be able to follow up with a scorecard of the whole process.

15) Conduct an evaluation of the effectiveness of social actions, having integrated social information.

MIGRAS wants to satisfy the following global objectives:

1) To develop an integral model of classification and grouping by need and consumption of social attention.

2) Extend a culture of balance and analytical control in the allocation of human, material and economic resources and in the adjustment of risks in social care, with special emphasis on dependency.

3) Establish parameters to predict the use of services and their budgetary adjustment, both in the financing of public and private institutions.

4) Value the introduction of redistribution elements in dependency budgets.

5) Identify elements of improvement in the budget distribution by geography, benefits...

These objectives can be formulated in an operative way as it is related below:

1) Calculate the magnitude and variability of the social care burden, expressed in Aggregated Sets of Social Care (CAAS), based on information from the information systems of the Ministry of Health, Social Services and Equality, and from which obtain by applying a user classification through the GRASS.

2) Obtain the average relative weights of the cost of assistance for each of the CAAS.

3) Stratify the use of resources in bands of resource use (BUR) that also allow to distinguish the proximity or risk of a jump in the degree of dependence and to calculate efficiency indices in the use of those resources.

4) Construct a general index to evaluate the efficiency in the budgetary distribution of resources. The index will include the various elements of the measurement of the quality of care, using structure data (expenditure at the primary and specialized levels), process (efficiency indices in resource utilization) and result (data to evaluate the quality of the indicators).

As specific objectives of the model we establish:

5) Establish the method to know the intragroup variability of the GRASS ob- 
tained according to the CMBDS coding of the social "highs" in the Social Care System and Social Stories and thus be able to group them in CAAS.

6) Approach a process management model based on their standardized design, reflected in the Integrated Social Care Guidelines (GIAS).

7) Define a methodological framework that will have to be applied to the allocation of costs of each of the GRASS:

8) Approach a model for the evaluation of the quality of social processes with tools that allow the sharing of results in the interests of quality and efficiency.

9) Construct a theoretical model to evaluate the efficiency in the distribution of resources, called the General Efficiency Index (EG). This model integrates structural variables (budget of personnel expenses and general expenses), process (indexes of efficiency in resources used in the calculation of GRASS / CAAS) and result (results of evaluation of a battery of indicators).

10) We start from the premise that it is possible to delimit certain homogeneous groups of users of social services based on a series of parameters, such as characteristics of the need or social problem involved, severity of the situation and type and intensity of services social services, and according to these, calculate the expense they generate.

11) For this, we must first classify all the users and for this we follow the reference of the Social Services Catalog: this gives rise to the GRASS. A later grouping, weighing this by the isoconsumo, leads us to obtain some sets of similar behavior that denominated CAAS (Aggregate Sets of Social Attention).

12) Next, the processes with ABQ methodology (Activity Base Quality, Activity-based Quality) are studied. This study will lead to the Integrated Social Care Guidelines (GIAS); and on these guides the Model of Assignment of Costs to the Processes of Social Attention (MACPAS) will be applied. The latter will be the basis for applying comparative models and evaluation of the quality of care. This can be done with the Tool for the Evaluation of Social Care Results (HERAS). From a sample of individuals, and variables such as: index of socioeconomic deprivation, consumption of resources at the primary level and specialized level, degree of disability and its temporal variation, a regression model could be made, obtaining a formula that simulates the spending on social care (dependence, risk of exclusion...) and its prognosis.

13) One of the fundamental elements of the MIRAS model is the tool for the allocation of costs to social assistance processes and very useful to assess the cost of each of the CAAS and finally, to establish and perform comparisons and benchmarking.

14) It constitutes the module of allocation of costs derived from the GRASS and CAAS by citizen for the different social cost centers. For this, it implements an accounting method that allocates the costs with an arborescent detail according to the total expenditure in a certain period of time.

15) MACPAS is the tool that allows modeling and defining a system of costs associated with social care processes. As in the field of health and in other areas, 
the need for a cost model becomes clear. For this reason, a cost-setting system based on the ABC methodology (Activity Based Costing) is introduced as support for social care processes.

16) Its philosophy is based on the principle that activities are really the causes that determine the consumption of resources and the subsequent costs. In the social field, this system identifies the activities carried out in the process and employs cost drivers (cost drivers) that allow the costs of these activities to be transferred to the different products or services based on the social processes carried out. In this way, the centers or departments incur costs as they carry out activities and the cost of the products is the result of the consumption of the activities necessary to obtain them. Therefore, excellence in cost management will require excellent management of activities. The principles of $\mathrm{ABC}$ systems can be applied to any type of organization and fit perfectly with the latest management trends, such as quality management models and reengineering or process redesign.

All these data contained in the Unique Social History (HSU), together with the classification of patients according to their etiology and needs (GRASS) obtained from the analysis of the specific social CMBD (CMBDS), and through a system of risk adjustment managed through an Aggregate Set of Social Attention (CAAS) that allows us to know the cost of social processes to be able to make comparisons (benchmarking) of efficiency and quality and allocate resources according to the costs obtained in the different processes of the catalog of social services, Later, it allows us to carry out Integrated Social Care Guidelines (GIAS) for the standardization of processes.

\section{Digitalizing the Chronic Patient and the Dependant}

Siesta TV is a cognitive accessible and usable platform of Ambient Intelligence (AmI), for the third generation of television using the Internet (IPTV), which allows the user bi-directionality and interactivity with multiple services in sectors such as health, leisure, culture and public services [55] [56]. Since in SiestaTV Cognitive the services can be consumed in different devices [57]. SiestaCare, allows offering a set of applications for patients, and professionals in the social-health sector. Through the intuitive interface, you can access the different uHealth services ranging from medical care with video consultations, e-check and hospitalization at home, to tele-education services for health, and clinical sessions between professionals with video ponencias, or broadcast in 3D by videostreaming, which allows to draw a real hospital scenario without barriers. SiestaCare is based on new interactive digital TV (IPTV) systems, this being a key tool in the new models of integrated health management and in the processes of socio-health care and care of people with dependence.

An example of this type of device is the iFreeTablet (Figure 7) and the Siesta Operating System [56] [58].

SiestaTV has several service verticals that can be reinterpreted to fulfill other 


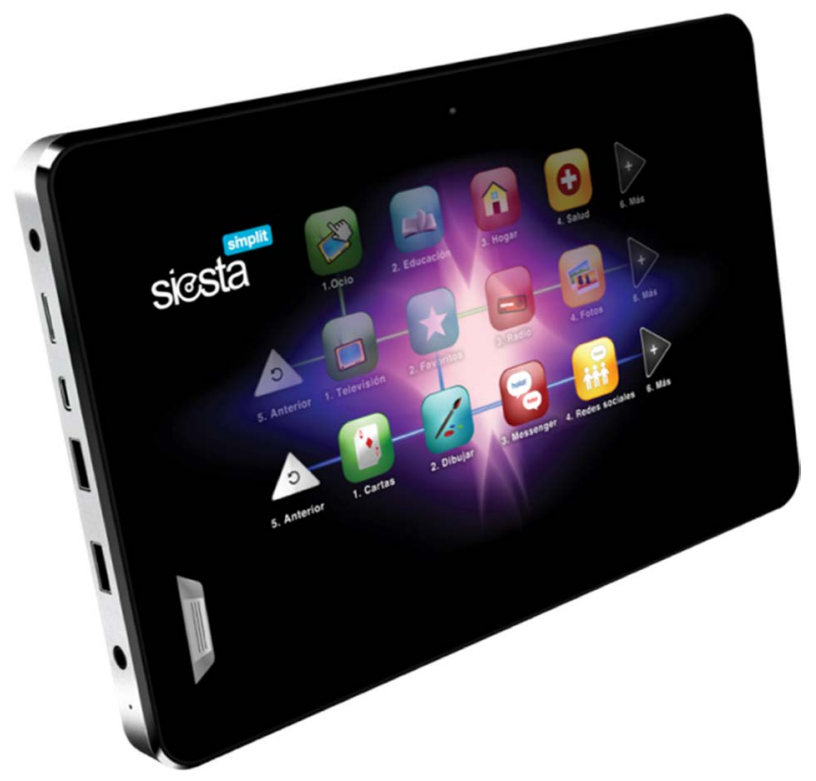

Figure 7. iFreeTablet.

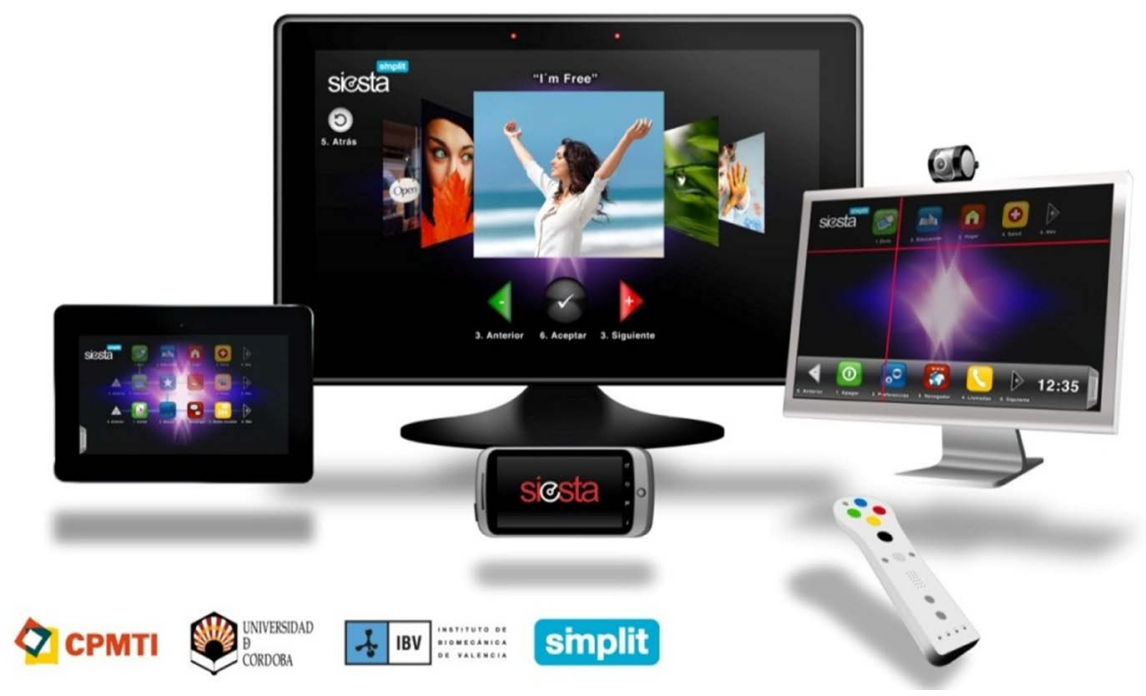

Figure 8. Siesta Care platform. Omnichannel services on Siesta TV.

functions [59] oriented to different sectors, among them the one of Health (SiestaCare) that allows access to primary care services where the doctor obtains data from patients, and patients can consult information. It allows simple non-invasive ambulatory tests such as measuring blood pressure, weight, pulse; via telematics. In addition, users can have access to diets, advice on eating habits, prevention, etc.

SiestaTV establishes a series of regulations and standards for accessible, usable and intelligent interactive digital TV and, as a consequence, the development of a series of author tools that allow the automation of the production processes of interactive multimedia programs for the IPTV, for consumption on any device and in mobility, as shown in Figure 8.

Siesta TV is a platform of Assisted Living in the Environment (AAL) that 
through techniques of Ambient Intelligence (AmI) and Cognitive Intelligence (CI) allows its integration in an environment of Ubiquitous City where the agile communication between users, the internet of things, advanced telematic services and new devices is done naturally, automatically, integrated and non-invasively or required.

The users are all citizens, with special attention and sensitivity towards the elderly and dependents, and on the other hand the agents that provide them with services: Public Administration, non-profit organizations and private operators, including caregivers and the family environment. However, Siesta TV contributes to the improvement in the accessibility to advanced services to the public.

The system allows spaces, objects and human activities to be managed in a usable and accessible manner, both in open spaces and closed spaces, in order to empower a citizen and the elderly in their natural surroundings, as well as to the lending agents of services (citizens, ...), although all are located in distributed spaces.

The platform and systems are imbued with the best practices of the industry to facilitate living according to the paradigm of active aging promoting future healthy seniors and providing greater autonomy to currently dependent people, the elderly today, their caregivers and your family environment Thus, new systems and interaction devices will be developed in the urban area, existing ones in the domestic sphere and all new devices will be integrated and the interfaces created will be accessible, usable and adaptive.

In short, it is proposed from the creation of the Ubiquitous City AAL platform to establish a series of regulations and standards for the ubiquitous friendly city accessible in general and as a consequence, the development of a series of tools that allow the automation of process and content generation techniques and their integration with spimes connected to the internet and people.

It allows, facing other systems, to enjoy full mobility without being subject to fixed devices or web environments, as well as to individualize the exact information to be transferred. In addition, the system is ready for the dissemination of intelligent information, such as value-added services. As a result, the system, in addition to the city services, may also send information of interest to the user who is sensitive to the context.

Siesta TV key value, is not only in its applicability in a new concept of future city, but lies in the multiplicity of derivative applications that can be generated from the developments that are obtained and that may be hosted in a multitude of economic areas generating new sources of value, and that in this project are focused on the field of Health, Culture, Sustainability and Public Services.

Siesta TV is focused on people, so all kinds of people with diversity are taking into account, people with special needs, people at risk of exclusion, etc. With special interest in the integration of services for the elderly in rural and urban areas. This system will enable the ability to integrate services-social and health resources, achieving real coordination. On the other hand, the system can serve 
to provide the service of prevention of dependence and promotion of personal autonomy whose development is in process and that has sometimes been linked to telecare although they are different services.

This solution will allow the municipalities, centers or users that use it, to integrate into the global movement of Friendly Cities with the Elderly and incorporates the vision of equity in the rural and urban areas of the national and international municipalities. First platform in the cloud that allows achieving that all the elements can be perfectly "integrated", "connected" and "interoperable".

Siesta TV has been designed around eight lines of specific research, structured and formally coordinated:

1) Reference models in the care of patients and dependence on international and national experience.

2) State of the art of information technologies applied to sick, elderly or disabled people.

3) Process and product development methodology.

4) Improvement and automation of the systems of continued geriatric socio-sanitary assistance.

5) Health programs.

6) Improvement and automation of home help systems.

7) Learning in Dependency Management and assistance to patients for informal caregivers, formal caregivers, technicians and end users.

8) Application of the previous sub-projects to a set of seven pilot floors and a nursing home, integrating the e-services and aids technologies.

Siesta TV is an ecosystem, a consequence of the development of digital communication. In Web 2.0 and its most recent versions Internet users are granted the status of prosumers-prosumers represents a contraction of the words producers and consumers. Prosumers can articulate new communication environments that are the result of the evolution of mobile digital communication. This revolution has transported us to a new socio-sanitary-cultural ecosystem: the ubiquitous society, only some lucky ones will be able to adapt quickly enough to be invited. Siesta TV, being an interactive ecosystem, accessible, usable, intelligent, ubiquitous and adaptive will allow access to any type of person, regardless of their diversity and economic situation, to adapt to this new paradigm of social integration.

Although many of these services are currently offered independently by other solutions, their fragmentation does not make possible their social "domestication" (or occurs very slowly). Siesta TV offers all the services architecture through the most used visualization and interaction devices currently: digital television, tablets and smartphones. To the extent that said service architecture is offered through a device perfectly assimilated and "domesticated" by society, Siesta TV intends to take advantage of the a priori acceptance of this device to introduce the services offered as part of daily activities (as it is already in fact the use of television). All the stakeholders around the chronic patient and the elder 
people have different needs of services. The most important of them to the patient are the caregivers. Siesta TV offers a range of services that cover needs of services of patients and caregivers (Figure 9), allowing the integration of the patients in the community, as the ICCC, ECCM and CCM models propose.

The users of Siesta Care will be given by categorizing them using the Kaiser pyramid. Those in the lower part of the pyramid will need technologies to access to socio-sanitary educational video content, FAQs, videoconference, social networks. Those in the upper part of the pyramid will need more technologies such as remote measuring, control of the adherence to treatment, domotics, emergency button, etc.

As we have discussed, technology is available to digitize many of the costly processes for health systems that chronics and dependents require. The biggest challenge is to map the technology to these processes. Using MIGRAS, it is possible to determine if a service is suitable in terms of quality, cost and effectiveness in a particular Health System, for a particular patient with particular chronic disease/s. This analysis is outside the scope of this paper but in any case, previous to a exhaustive calculation, most of the technologies of Siesta TV, will cover most of the required services to be provided.

Siesta TV is based on the design of interactive person-TV interaction interfaces and supported by Advanced Environmental Intelligence Technologies

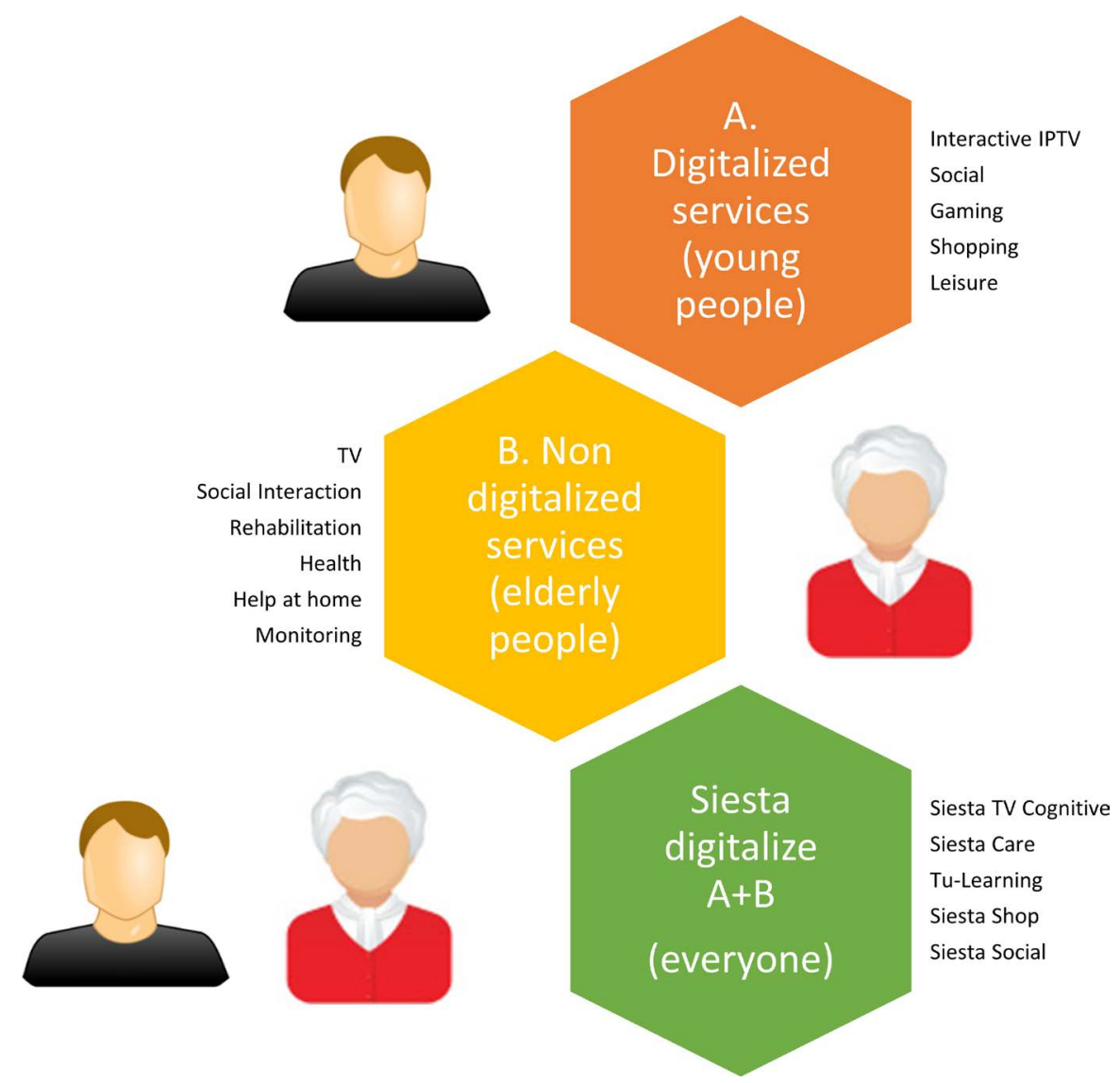

Figure 9. New paradigm of digitalization of services on Siesta TV. 
integrated in a single cloud-computing platform, with a series of vertical modules that allow:

1) Access to general information of interest.

2) Access accessible and adaptive training resources, ensuring an individualized remote monitoring of the learning and understanding process.

3) Control of the home automation system installed in the home or hospital room.

4) Participation in a collaborative space with professionals and other users of similar interests.

5) Task planning system to establish standard telephone communications, IP telephony or videoconference with family, friends or with an external "contact-center".

6) System of remote supervised consultations, adoption of healthy life habits programs.

7) Automatic help system for decision making.

8) System of continuous monitoring of vital parameters that facilitates programs of rehabilitation and early detection or rehabilitation of cognitive problems.

9) Chronic disease monitoring: Situation monitoring and control system.

10) Adaptive checkup systems.

11) Dependency Prevention and Treatment System.

And horizontal features as:

12) Ubiquity: Allows the user to use the system anywhere, anyhow.

13) Usability.

14) Accesibility (WAI-AAA and WCAG 2.0).

15) Cognitive computing.

16) Ambient Intelligence.

17) Recommender agents.

\section{Conclusions}

In this scenario, managing the chronic patient will be achieved by surrounding him/her by autonomous sensors (scales, tensiometers, ECG recorders, and other devices that can be implanted in the skin or tissues, through environmental sensors of temperature, humidity, position, etc. that forming ad hoc networks, be they BAN (Body Area Network), PAN (Personal Area Network) and/or HAN (Home Area Network), which will acquire and transmit all the information of interest. Actors involved in health care can act in synergy, improving the quality of care and the efficiency of the Health System, which are the main challenges facing current medicine and the immediate future. Ubiquitous omnichannel experience will be also fundamental to allow all the different stakeholders to interact with the systems and the people.

The key will facilitate personal autonomy and increase the quality of life of people with functional diversity trying to extend the new values of e-Inclusion 
such as Normalization, Difference, Health and Competition.

Solutions of integral management of e-services, assistive technologies and techniques for the prevention, monitoring and treatment of dependence aimed at chronic patients, elderly or with some kinds of functional diversity should be open and non-captive. Furthermore, after usability lab testing of Siesta TV [55], we expect online, modular, interoperable, multimodal, accessible, usable, adaptive and flexible systems will be able to cover the needs of the patient, the stakeholders and the National Health Systems. These solutions will strengthen and improve the current health and social assistance systems in order to increase the quality of life and the possibility of an independent life of these people in the hospital, residences, home or family environment, cutting out the stays outside the home. In the near future, the immersion in technologies of ubiquitous computing, environmental intelligence and the natural interfaces in telecare and telemedicine will be something that we will all use regularly.

All these techniques will enhance the world of medicine, realizing in the medium term a total paradigm shift in the field of comprehensive management of socio-health care.

\section{References}

[1] Buttery, C. (2015) Adult Social Care Statistics. Health and Social Care Information Centre, Leeds.

[2] Bengoa, R. and Nuño, R. (2008) Curar y Cuidar. Innovación en la gestión de enferemedades crónicas: Una guía práctica para avanzar. Elsevier-Masson, Barcelona.

[3] Boult, C., Kane, R.L. and Brown, R. (2000) Managed Care of Chronically Ill Older People: The US Experience. BMJ, 321, 1011-1014.

https://doi.org/10.1136/bmj.321.7267.1011

[4] Cabo Salvador, J. (2009) La Reforma Sanitaria y sus Instrumentos de Gestión: Editorial Adalia Farma.

[5] Cabo Salvador, J., Herreros Gonzalez, J., Cabo Muiños, V., Bellmont Lerma, M.A., Garcia Jiménez, E. and Vilches Martinez, M. (2014) Plan Estratégico de Gestión de las Organizaciones Sanitarias. Gestión Clínica y Gobierno Clínico. En Reunió d'experts: Innovant en prevenció cardiovascular i eficiencia. Price Waterhouse Coopers, Barcelona.

[6] Cabo Salvador, J., Cabo Muiños, J. and Roberto Iglesias, J. (2010) Sistemas de Salud y Reformas. Centro de Estudios Financieros, 31-84.

[7] Charlson, M., Charlson, R.E., Briggs, W. and Hollenberg, J. (2007) Can Disease Management Target Patients Most Likely to Generate High Cost? The Impact of Comorbidity. Journal of General Internal Medicine, 22, 464-469. https://doi.org/10.1007/s11606-007-0130-7

[8] Epping-Jordan, J.E., Pruitt, S.D., Bengoa, R. and Wagner, E.H. (2004) Improving the Quality of Health Care for Chronic Conditions. Quality and Safety in Health Care, 13, 299-305. https://doi.org/10.1136/qshc.2004.010744

[9] Kane, R., Keckhafer, G. and Robst, J. (2002) Evaluation of the Evercare Demonstration Program. Final Report to the Centers for Medicare and Medicare and Medicaid Services, University of Minnesota, Minnesota. 
[10] Kreindler, S. (2008) Lifting the Burden of Chronic Disease. http://www.longwoods.com/articles/images/ChronicDiseaseReport.pdf

[11] Medicare Payment Advisory Commission (2007) Report to Congress: Promoting Greater Efficiency in Medicare. Medicare Payment Advisory Commission, Washington DC.

http://www.medpac.gov/docs/default-source/reports/Jun07_EntireReport.pdf

[12] National Public Health Service for Wales (2006) International Overview of the Evidence on Effective Service Models in Chronic Disease Management. Welsh Assembly Government, Cardiff.

[13] Rosen, R. and Ham, C. (2008) Integrated Care: Lessons from Evidence and Experience. Nuffield Trust, Birmingham.

[14] Russell, G., Thille, P., Hogg, W. and Lemelin, J. (2008) Beyond Fighting Fires and Chasing Tails? Chronic Illness Care Plans in Ontario. The Annals of Family Medicine, 6, 146-153. https://doi.org/10.1370/afm.793

[15] Singh, D. and Ham, C. (2006) Improving Care for People with Long-Term Conditions. A Review of UK and International Frameworks. University of Birmingham (HSMC), Institute for Innovation and Improvement (NHS), Birmingham.

[16] Arshad, P., Oxley, H., Watts, S., Davenport, S. and Sermin, N. (2000) Systematic Approach to Community Risk Assessment and Management. British Journal of Nursing, 9, 210-214. https://doi.org/10.12968/bjon.2000.9.4.6378

[17] Bleaglehole, R.B., Epping-Jordan, J.E., Patel, V., Chopra, M., Ebrahim, S., Kidd, M. and Haines, A. (2008) Improving the Prevention and Management of Chronic Disease in Low-Income and Middle Income Countries: A Priority for Primary Health Care. The Lancet, 372, 940-949. https://doi.org/10.1016/S0140-6736(08)61404-X

[18] Bodenheimer, T. and Berry-Millet, R. (2009) Care Management of Patients with Complex Health Care Needs.

https://www.rwjf.org/en/library/research/2009/12/care-management-of-patients-wit h-complex-health-care-needs.html

[19] Barr, V.J., Robinson, S., Marin-Link, B., Underhill, L., Dotts, A., Ravensdale, D. and Salivaras, S. (2003) The Expanded Chronic Care Model: An Integration of Concepts and Strategies from Population Health Promotion and the Chronic Care Model. Hospital Quarterly, 7, 73-82. https://doi.org/10.12927/hcq.2003.16763

[20] Boult, C., Reider, L., Frey, K., Leff, B., Boyd, C.M., Wolff, J.L., Wegener, S., Marstellar, J., Karm, L. and Scharfstein, D. (2008) Early Effects of "Guided Care" on the Quality of Health Care for Multimorbid Older Persons: A Cluster-Randomized Controlled Trial. The Journals of Gerontology. Series A, Biological Sciences and Medical Sciences, 63, 321-327. https://doi.org/10.1093/gerona/63.3.321

[21] Boyd, C.M., Boult, C., Shadmi, E., et al. (2007) Guided Care for Multi-Morbid Older Adults. Gerontologist, 47, 697-704. https://doi.org/10.1093/geront/47.5.697

[22] Cabo Salvador, J. and Bellmont Lerma, M.A. (2014) Gestión de la Calidad en las Organizaciones Sanitarias: Sistemas Sanitarios y Reformas Sanitarias. Enfoque hacia la calidad. Ediciones Díaz de Santos, 1-48.

[23] Eklund, K. and Wilhemson, K. (2009) Outcomes of Coordinated and Integrated Interventions Targeting Frail Elderly People: A Systematic Review of Randomised Controlled Trials. Health Soc Care Community, 17, 447-458. https://doi.org/10.1111/j.1365-2524.2009.00844.x

[24] Hroscikoski, M.C., Solberg, L.L., Sperl-Hillen, J.M., McGrail, M.P. and Crabtree, B.F. (2006) Challenges of Change: A Quantitative Study of Chronic Care Model Implementation. The Annals of Family Medicine, 4, 317-326.

https://doi.org/10.1370/afm.570 
[25] Weiser, M. (1991) The Computer of the 21st Century. Scientific American, 265, 94-104. https://doi.org/10.1038/scientificamerican0991-94

[26] Weiser, M. (1993) Some Computer Science Issues in Ubiquitous Computing. Communications of the ACM, 36, 75-84. https://doi.org/10.1145/159544.159617

[27] Weiser, M. and Brown, J.S. (1996) The Coming of Calm Technology. Xerox PARC, Palo Alto.

[28] Waldner, J.-B. (2007) Inventer l'Ordinateur du XXIeme Siècle. Hermes Science, London.

[29] Sterling, B. (2005) Shaping Things. MIT Press, Cambridge.

[30] Instituto para la Diversificación y el Ahorro Energético. http://www.idae.es http://www.idae.es/index.php/id.147/mod.noticias/mem.detalle

[31] World Commission on Environment and Development (1987) Development and International Economic Co-Operation: Environment. United Nations, New York.

[32] Alusi, A., et al. (2011) Sustainable Cities: Oxymoron or the Shape of the Future. Harvard Business School, Cambridge.

[33] Wagner, E.H. (1998) Chronic Disease Management: What Will It Take to Improve Care for Chronic Illness? Effective Clin Practice, 1, 2-4.

[34] Cabo Salvador, J. (2010) Gestión de la Calidad con un Enfoque Basado en Procesos. Gestión Calidad y Logística Hospitalaria. Editorial Adalia Farma.

[35] Trace Research and Development Center. http://trace.wisc.edu

[36] Gravelle, H., Dusheiko, M., Sheaff, R., Sargent, P., Boaden, R., Pickard, S., Parker, S. and Roland, M. (2007) Impact of Case Management (Evercare) on Frail Patients: Controlled before and after Analysis of Quantitative Outcome Data. BMJ, 334, 31-34. https://doi.org/10.1136/bmj.39020.413310.55

[37] Morgan, M.W., Zamora, N.E. and Hindmarsh, M.F. (2007) An Inconvenient Truth: A Sustainable Healthcare System Requires Chronic Disease Prevention and Management Transformation. Healthcare Papers, 7, 6-23. https://doi.org/10.12927/hcpap.2007.18992

[38] Pearson, M.L., Wu, S., Schaefer, J., Bonomi, A.E., Shortell, S.M., Mendel, P.J., Marsteller, J.A., Louis, T.A., Rosen, M. and Keeler, E.B. (2005) Assessing the Implementation of the Chronic Care Model in Quality Improvement Collaboratives. Health Services Research, 40, 978-996. https://doi.org/10.1111/j.1475-6773.2005.00397.x

[39] Nuño, R. (2007) Buenas prácticas en gestión sanitaria: El caso Kaiser Permanente. Revista de Administración Sanitaria, 5, 283-292.

[40] Sevick, M.A., Trauth, J.M., Ling, B.S., Anderson, R.T., Piatt, G.A., Kilbourne, A.M. and Goodman, R.M. (2007) Patients with Complex Chronic Diseases: Perspectives on Supporting Self-Management. Journal of General Internal Medicine, 22, 438-444. https://doi.org/10.1007/s11606-007-0316-Z

[41] Sheaff, R., Boaden, R., Sargent, P., Pickard, S., Gravelle, H., Parker, S. and Roland, M. (2009) Management for Frail Elderly People: A Qualitative Study. Journal of Health Services Research \& Policy, 14, 88-95. https://doi.org/10.1258/jhsrp.2008.007142

[42] Tinetti, M.E., Bogardus, S.T. and Agostini, J.V. (2004) Potential Pitfalls of Specific Disease Guidelines for Patients with Multiple Conditions. The New England Journal of Medicine, 351, 2870-2874. https://doi.org/10.1056/NEJMsb042458

[43] Cabo Salvador, J., Bellmont Lerma, M.A., Cabo Muiños, J. and Cabo Muiños, V. (2014) Gestión de la Calidad en las Organizaciones Sanitarias: Ajustes de riesgos y 
calidad asistencial. Agrupadores (APG, GRD, AP-GRD, IR-GRD, ACG, DxCG, CRG). Ediciones Díaz de Santos, Madrid, 1157-1210.

[44] Cabo Salvador, J., Bellmont Lerma, M.A., Cabo Muiños, J. and Cabo Muiños, V. (2014) Gestión de la Calidad en las Organizaciones Sanitarias: Ajustes de riesgos y calidad asistencial. Pago Capitativo, Riesgo Moral, Demanda Inducida y Selección de Riesgos. Ediciones Díaz de Santos, Madrid, 1115-1156.

[45] Ouwens, M., Wollersheim, H., Hermens, R., Hulscher, M. and Grol, R. (2005) Integrated Care Programmes for Chronically Ill Patients: A Review of Systematic Reviews. International Journal for Quality in Health Care, 17, 141-146. https://doi.org/10.1093/intqhc/mzi016

[46] Sylvia, M., Griswold, M., Dunbar, L., Boyd, C.M., Park, M. and Boult, C. (2008) Guided Care: Cost and Utilization Outcomes in a Pilot Study. Disease Management, 11, 29-36. https://doi.org/10.1089/dis.2008.111723

[47] Tsai, A.C., Morton, S.C., Mangione, C.M. and Keeler, E.B. (2005) A Meta-Analysis of Interventions to Improve Care for Chronic Illnesses. Canadian Family Physician, 54, 1655-1658.

[48] Upshur, R.E.G. and Tracy, S. (2008) Chronicity and Complexity: Is What's Good for the Disease Good for the Patients. Effective Clinical Practice, 1, 2-4.

[49] Weiss, K.B. (2007) Managing Complexity in Chronic Care: An Overview of the VA State-of-the-Art (SOTA) Conference. Journal of General Internal Medicine, 22, 374-378. https://doi.org/10.1007/s11606-007-0379-x

[50] Ramos López, J., Soguero Ruiz, C., Mora Jiménez, I., Rojo Álvarez, J.L. and Cabo Salvador, J. (2014) Gestión de la calidad en las Organizaciones Sanitarias: M-Health y su impacto en la caliad asistencial. Ediciones Díaz de Santos, Madrid, 1009-1052.

[51] Lopez Coronado, M., de la Torre, I., Herreros Gonzalez, J. and Cabo Salvador, J. (2014) Gestión de la Calidad en las Organizaciones Sanitarias. Calidad Asistencial mediante la Telemedicina y la Teleasistencia. Ediciones Díaz de Santos, 933-952.

[52] Coleman, K., Austin, B.T., Brach, C. and Wagner, E.H. (2009) Evidence on the Chronic Care Model in the New Millenium. Health Affairs, 28, 75-85. https://doi.org/10.1377/hlthaff.28.1.75

[53] Sajardo Moreno, S., Núñez Suárez, J.C. and Cabo Salvador, J. (2010) Gestión Sanitaria Integral: Pública y Privada. Enfoque para la implantación de una Historia de Salud a nivel Regional/Nacional. Editorial Centro de Estudios Financieros, 513-560.

[54] WHO (2002) Innovative Care for Chronic Conditions: Building Blocks for Action. Global Report WHO/NMC/CCH, Geneva.

[55] Castro, C., Ramírez, J.M., et al. (2010) Siesta: Aid Technology and e-Service Integrated System. ADNTIIC, 1559-1570.

[56] Castro, C., Ramírez, J.M., et al. (2010) Siesta: From Concept Board to Concept Desktop. HCITOCH, 173-183.

[57] Fernandez, B., Javier, F., et al. (2013) Mando a distancia virtual usable para la interacción con la televisión ubicua. Revista Cubana de Ciencias Informáticas, 7, 74-84.

[58] Castro, C., Ramírez, J.M., et al. (2010) Usable Interface Design for Everyone. HCITOCH, 157-172.

[59] Ramírez, J.M., de Castro, C., Robles, R.M., García, E. and Burón, F.J. (2012) Televisión Digital en ciudades ubicuas. http://sedici.unlp.edu.ar/ http://sedici.unlp.edu.ar/handle/10915/25933 